\title{
POLUIÇÃO AMBIENTAL E ALERGIA RESPIRATÓRIA
}

\author{
ENVIRONMENTAL POLLUTION AND RESPIRATORY ALLERGY
}

Miguel croce ${ }^{1}$, Dewton M. Vasconcelos², Eliúde R. C. Manso ${ }^{1}$ \& Alberto J. S. Duarte ${ }^{2}$

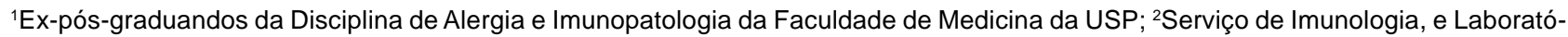
rio de Imunogenética e Transplante Experimental do Hospital das clínicas da Faculdade de Medicina da USP.

CoRRESPONDÊNCIA: Dewton de Moraes Vasconcelos - Laboratório de Imunogenética e Transplante Experimental do Hospital das Clínicas da Faculdade de Medicina da Universidade de São Paulo - Av. Dr. Arnaldo, 455, 2ํandar, sala 2345, Cerqueira césar, São Paulo - SP, CEP: 01246-903 - Telefones: 011-3066-7457 ou 3066-7499 - Fax: 011-3064-0879 ou 881-7190 - e-mail: dmvascon@usp.br
\end{abstract}

CROCE M et al. Poluição ambiental e alergia respiratória. Medicina, Ribeirão Preto, 31: 144-153, jan./mar. 1998.

RESUMO: Na primeira parte desta revisão, são apresentados os principais agentes biológicos e não biológicos que funcionam como poluentes atmosféricos em ambientes domiciliares. Em seguida, discutem-se os mecanismos pelos quais estes poluentes contribuem para a patogênese de doenças respiratórias, principalmente alérgicas. Finalmente, demonstra-se como o controle ambiental, instituído em uma zona industrial diariamente poluída próxima à cidade de São Paulo, reduziu tanto a emissão de poluentes como a prevalência de doenças respiratórias.

UNITERMOS: Poluição Ambiental. Hipersensibilidade Respiratório. Alergia e Imunologia

\section{INTRODUÇÃO}

Diariamente, mobilizamos de dez mil a vinte mil litros de ar, daí que, inevitavelmente, o trato respiratório está exposto a diversos tipos de poluentes, sejam gasosos, particulados ou fibrosos. Apesar dessas impurezas, as defesas respiratórias conseguem, na maioria das vezes, evitar danos e manter a função pulmonar em equilíbrio.

Não obstante, a poluição ambiental provoca uma série de transtornos na vida diária do ser humano. Os dados notificados em numerosos estudos, epidemiológicos e de registro ambiental, mostram um aumento persistente de diversas doenças alérgicas, como a asma, nas últimas décadas ${ }^{(1 / 3)}$. Paralelamente, neste mesmo período, tem-se demonstrado o incremento das concentrações de vários poluentes atmosféricos, como o dióxido de nitrogênio $\left(\mathrm{NO}_{2}\right)$, ozônio $\left(\mathrm{O}_{3}\right)$, dióxido de enxofre $\left(\mathrm{SO}_{2}\right)$, partículas "não-determinadas", respiráveis, menores que 10 micras $\left(\mathrm{PM}_{10}\right)$, e produtos químicos e orgânicos voláteis (POV).

Estudos realizados no Japão e na Alemanha têm demonstrado que quanto maior for a emissão de polu- entes por veículos automotores, movidos a diesel, maior é a incidência de rinoconjuntivite e bronquite ${ }^{(4,5)}$. No Brasil, investigações realizadas pelo Laboratório de Poluição Atmosférica Experimental da Faculdade de Medicina da Universidade de São Paulo, mostram que, em São Paulo, nos dias de maior poluição, o número de internações por problemas respiratórios aumenta $65 \%$, em crianças de até treze anos ${ }^{(6)}$.

Apesar de que, hoje em dia, se tenha um melhor conhecimento da patogênese da asma, contando-se inclusive, com medidas terapêuticas mais eficientes, sua incidência vem aumentando. A forma como entendemos a asma também modificou. A asma não é uma condição dependente de um estado alterado do músculo liso, mas, em vez disso, é um processo inflamatório no qual a mucosa respiratória participa ativamente.

\section{A POLUIÇÃO DENTRO DE NOSSOS DOMICÍLIOS}

Muitos agentes biológicos e não-biológicos contaminam o interior de casas e ambientes de trabalho. 
Os agentes biológicos mais prevalentes são: vírus, bactérias, fungos, algas, amebas, pólens, ácaros, insetos, epitélios de animais e de seres humanos. A maioria das bactérias, dentro de ambientes fechados, têm como fontes os próprios humanos, enquanto que a maioria dos fungos provêm do espaço externo. Dentre as substâncias não-biológicas, temos as partículas provenientes do fumo do cigarro e dos produtos de combustão, os gases $\mathrm{CO}, \mathrm{CO}_{2}, \mathrm{NO}, \mathrm{NO}_{2}$, radônio, formaldeído, compostos orgânicos semivoláteis.

Tendo em conta que cada meio-ambiente doméstico interno é único, mesmo de quarto a quarto, sabe-se que a forma mais fácil de gerar poluição é uma ventilação deficiente. Em edifícios com sistemas de ar condicionado, contaminados por microorganismos, o problema é semelhante. Os materiais de construção, de limpeza e de pintura liberam poluentes continuamente, tanto como o simples ato de fumar dentro de $\operatorname{casa}^{(7)}$.

O princípio essencial para controlar o ar do meio interno é identificar, remover, isolar ou substituir a fonte poluidora. Na prática isto não é fácil. A parte econômica pesa bastante na hora de decidir. Tal é o caso da substituição de móveis contaminados, assim como a modificação de sistemas de ventilação em um edifício e inclusive a simples manutenção deste equipamento.

Entre as fontes poluídoras do meio ambiente doméstico temos (Tabela I):

Tabela I - Fontes de poluição no ambiente doméstico

Agentes não-biológicos

- Partículas "não determinadas" respiráveis

- NO, NO2

- $\mathrm{CO}, \mathrm{CO} 2$

- Formaldeído

- Radônio

- Compostos orgânicos

- Voláteis e semivoláteis

Asbestos

Agentes biológicos

- Acáros do pó doméstico: Dermatophagoides sp, Blomia tropicalis

- Acáros de estocagem (em alimentos e vegetais armazenados)

- Fungos, vírus, bactérias, endotoxine bacteriana

- Gatos, cães e outros animais domésticos

- Insetos: baratas e outros.

\section{a) Agentes não-biológicos}

- Partículas “não-determinadas” respiráveis $\left(\mathbf{P M}_{10}\right)$ : originadas a partir de fogueiras, queima de madeira e carvão, cozinhas a querosene e cigarro. A Agência Norte-Americana de Controle de Meio Ambiente estabelece $265 \mu \mathrm{g} / \mathrm{m}^{3}$ como limite máximo tolerável. Concentrações maiores que $500 \mu \mathrm{g} / \mathrm{m}^{3}$ podem ser detectadas em restaurantes, salas de espera e bares; entre 100 a $500 \mu \mathrm{g} / \mathrm{m}^{3}$ nas seções de fumantes, em aviões, e entre 10 a $100 \mu \mathrm{g} / \mathrm{m}^{3} \mathrm{em}$ casas. As principais queixas causadas por essas partículas respiráveis são: irritação ocular, nasal e de garganta, infecções respiratórias e bronquites, cefaléias, havendo inclusive evidências de que possa aumentar a incidência de câncer pulmonar ${ }^{(8)}$.

- NO e NO²: as fontes usuais de $\mathrm{NO}$ e $\mathrm{NO}_{2}$ são as emanações de gás, pilotos de luz, cozinhas e estufas a gás e querosene, máquinas a gasolina, fumo de cigarro. A OMS estima que é segura uma exposição por uma hora a 160 ppb. Em casas com cozinhas a gás se detectam de 25 a 75 ppb. Em cozinhas a gás de querosene, se podem detectar entre 100 a 500 ppb. A exposição a $\mathrm{NO}_{2}$ pode produzir irritação ocular, nasal e de garganta. A inalação de $\mathrm{NO}_{2}$ pode alterar a função respiratória e aumentar as infecções em crianças.

- $\mathrm{CO}, \mathrm{CO}_{2}$ : o fumo do cigarro, lampiões a querosene, aquecedores de água a gás, fogões e cozinhas a lenha, além dos motores a gasolina, são importantes fontes de CO. Em baixos níveis, a inalação causa fadiga e dor torácica, em pacientes com patologia isquêmica do miocárdio. Em maiores concentrações, visão borrada, distúrbios de coordenação, cefaléias, tontura, confusão, náusea e eritema cutâneo, reversível tão logo se saia do ambiente poluído. A inalação de altas concentrações de CO pode ser fatal. Em domicílios que não possuem aparelhos a gás, a concentração varia entre 0,5 a $5 \mathrm{ppb}^{(9)}$.

O próprio ser humano, fogões a gás propano, e o fumo do cigarro são as principais fontes domésticas de $\mathrm{CO}_{2}$. Sua concentração, no exterior das casas, varia entre 320 a 400 ppm. Concentrações entre 2000 a $5000 \mathrm{ppm}$ podem ser encontradas em residências mal ventiladas. Concentrações de $\mathrm{CO}_{2}$, menores que 1000 ppm, indicam boa ventilação.

- Formaldeído: é um composto orgânico, volátil, presente em isolantes de espuma de uréia-formaldeído, colas, fibra plástica, cartões prensados, madeira compensada e base de tapetes. As concentrações de formaldeído variam entre 0,1 a $0,8 \mathrm{ppm}$ em 
domicílios com isolantes de espuma. Nas casas móveis, "motorhomes", as concentrações são, em média, de $0,5 \mathrm{ppm}$. A exposição a formaldeído pode produzir irritação ocular, de garganta, náusea e dificuldades respiratórias. Estima-se que concentrações entre 0,2 a 0,5 ppm são aceitáveis.

- Radônio: elemento gasoso, radioativo, pesado, do grupo de gases inertes. É formado a partir da desintegração do rádio. As principais fontes são a terra contaminada com detritos industriais, hospitalares e de aterro urbano, assim como as rochas que se encontram por debaixo das casas, poços de água e alguns materiais de construção. Este gás pode penetrar nas casas através de fissuras nas paredes de concreto, drenagens dos pisos, e chega a ser um problema quando acomete edifícios. A exposição a radônio não produz sintomas imediatos. Tem sido sugerido que a exposição a este gás seria responsável por $10 \%$ dos cânceres de pulmão, nos Estados Unidos da América, sendo os fumantes os que têm maior risco para desenvolver câncer de pulmão induzido por radônio.

- Componentes orgânicos voláteis e semivoláteis: as fontes típicas de componentes orgânicos voláteis são produtos de uso doméstico: pinturas, aerosóis "sprays" e artigos de pintura. Os efeitos mais comuns e conhecidos são irritação ocular, nasal, de garganta e cefaléia. Há relatos de alteração na coordenação, náusea, dano hepático, renal e do sistema nervoso central. Os níveis destes poluentes, no interior das casas, são, muitas vezes, maiores que no exterior e, em alguns casos, podem alcançar várias ordens de magnitude, sobretudo depois de usados removedores de pintura. As fontes mais importantes de componentes orgânicos semivoláteis, (hidrocarbonetos clorados e compostos policíclicos) são: pesticidas, fungicidas, herbicidas, combustão de madeira, tabaco e querosene.

- Asbestos: as principais fontes, dentro de casa, são os isolantes deteriorados, as coberturas de asbesto e alguns tanques de água.

\section{b) Agentes biológicos}

As principais fontes são os gatos, cães, insetos, fungos, bactérias, baratas e ácaros.

O pó de casa é a principal fonte de alérgi$\cos _{\text {domésticos }}{ }^{(10)}$. É composto por fibras, esporos de fungos, pólens, fragmentos e fezes de insetos, epitélios de animais e ácaros ${ }^{(11,12)}$.

Entre os animais de estimação, os gatos são os que mais sensibilizam, ainda que outros animais, como cães, camundongos, pássaros, coelhos, "hamsters" e outros possam também sensibilizar (epitélios, saliva, secreções e urina). As proteínas de aves podem produzir pneumonias, o que é mais ou menos freqüente entre os criadores de pombos.

Os fungos também constituem uma importante fonte de alérgenos, em casas que possuem um ambiente úmido. Agentes infecciosos, como vírus e bactérias, também são constantes no ambiente domiciliar. Valeria a pena ressaltar que as endotoxinas bacterianas são potentes substâncias proinflamatórias, que podem agravar a asma ou induzir broncoespasmo. Michel et al. ${ }^{(13)}$ demonstraram que a inalação de lipopolissacarídeos (o principal componente das endotoxinas) induz broncoconstrição e um aumento de hiperreatividade brônquica, inespecífica, em asmáticos.

- Pó de casa e ácaros: A contaminação da casa por estes artrópodes se dá através de partículas resultantes de fragmentos do corpo, de suas secreções e fezes. A principal família é a Pyroglyphidae, que consiste em dezessete gêneros e quarenta e sete espécies. A maioria vive em ninhos e parasita animais pequenos, porém onze espécies de cinco gêneros são encontradas em casas. O Dermatophagoides pteronyssinus, Dermatophagoides farinae e o Euroglyphus maynei são os mais importantes. No Brasil, a Blomia tropicalis tem posição de destaque, devido à sua elevada prevalência em quase todas as regiões estudadas. As condições ótimas para o crescimento são uma temperatura entre $22^{\circ} \mathrm{C}$ a $26^{\circ} \mathrm{C}$ e $75 \%$ de umidade relativa, freqüentemente encontradas nos domicílios.

Os ácaros não podem viver, quando a umidade relativa for menor que $50 \%$. A altitude também afeta sua sobrevivência, porém, por seus efeitos sobre a temperatura e a umidade. Na Suíça e França, em altitudes maiores que $1200 \mathrm{~m}$, o número e as espécies de ácaros diminuem, provavelmente, pela baixa temperatura e umidade. Estudos realizados nesses países $^{(14 / 15)}$ mostram que os asmáticos alérgicos a ácaros melhoram quando passam a viver naquelas regiões. Isso pode não ocorrer em nossas regiões andinas, como na Colômbia, onde a alta umidade promove o crescimento de ácaros mesmo em grandes altitudes ${ }^{(16)}$. Tem-se demonstrado que os níveis mínimos de sensibilização por ácaros apresentamse na concentração de $2 \mu \mathrm{g}$ por grama de pó ${ }^{(17)}$.

Existem também os ácaros de estocagem, que habitam alimentos e vegetais armazenados e também possuem capacidade sensibilizante. As espécies mais 
comuns pertencem aos gêneros Tyrophagus, Glycyphagus, Acarus, Lepidoglyphus, Chortoglyphus, Caloglyphus, Aleuroglyphus e Tarsonemus. Esses ácaros encontram-se nos grãos, celeiros, palha e feno armazenados e podem contaminar o pó da casa. Em um estudo realizado em supermercados de São Paulo, detectou-se que alguns pacotes de cereais, feijão, arroz e talharim se encontravam contaminados por esses ácaros (sobretudo naqueles que haviam estado, por várias semanas, nas estantes, ou com os prazos de validade vencidos).

\section{- Animais de estimação}

Gatos: os gatos possuem proteínas consideradas como potentes sensibilizadoras. Calcula-se que entre 9 a $41 \%$ dos asmáticos são sensibilizados a alérgenos de gatos. Os principais alérgenos se encontram na pele, saliva e urina desses animais ${ }^{(18)}$. Cães: 5 a $30 \%$ dos indivíduos alérgicos estão sensibilizados a antígenos derivados de cães, que se encontram presentes na saliva, descamação epidérmica, soro, fezes e urina ${ }^{(19)}$.

Insetos: As baratas constituem uma fonte de alérgenos dentro das casas, podendo ser causa de broncoespasmos graves, em asmáticos sensibilizados. Estima-se que, nos Estados Unidos, em residências de famílias de poder aquisitivo mais baixo, mais de $50 \%$ dos asmáticos alérgicos encontram-se sensibilizados a fragmentos, fezes ou secreções de baratas. No entanto, uma rápida avaliação na América Latina não parece confirmar esses altos índices.

\section{PRINCÍPIOS DO DANO RESPIRATÓRIO POR POLUENTES}

Na patogênese das enfermidades respiratórias induzidas pelo meio ambiente participam diversos mecanismos, como o intercâmbio gasoso, a deposição do pó inalado e sua subseqüente eliminação ou retenção. (Tabela II).

Tabela II - Mecanismos patogênicos da lesão respiratória por poluentes ambientais

Captação de Gases:

- depende de sua solubilidade em água e lipídios

Deposição e retenção de partículas:

- depende do seu tamanho

Interferência com o sistema mucociliar:

- diminuição da elasticidade do muco na poluição exacerbada

\section{a) Captação de gases}

Gases altamente hidrossolúveis, como o $\mathrm{SO}_{2}$, acroleína ou formaldeído são facilmente absorvidos pelo nariz e faringe, em breves e curtas exposições. O formaldeído é absorvido primariamente nas vias respiratórias altas (nariz) devido à sua elevada solubilidade. Têm sido descritos casos de câncer de nariz em trabalhadores expostos a formaldeído por muitos anos ${ }^{(20)}$.

Por outro lado, gases menos hidrossolúveis, como $\mathrm{NO}_{2}$ ou $\mathrm{O}_{3}$, conseguem penetrar profundamente no trato respiratório. Nesse sentido, o monóxido de carbono (CO), por ser pouco solúvel, é absorvido a nível alveolar, onde é rapidamente ligado à hemoglobina, produzindo efeitos sistêmicos, como cefaléia, dor torácica e confusão mental, além do dano pulmonar ${ }^{(9)}$. O exercício pode aumentar a captação de gases, ao passar de uma ventilação nasal a uma oral.

\section{b) Deposição e retenção de partículas e fibras}

As partículas maiores que $10 \mu \mathrm{m}$ são efetivamente filtradas no nariz e nasofaringe. As partículas presas são depuradas nas secreções nasais, podendo ser eliminadas pela tosse ou deglutidas. As partículas menores que $10 \mu \mathrm{m}\left(\mathrm{PM}_{10}\right)$ se depositam na árvore brônquica, sobretudo aquelas com diâmetros de $1 \mathrm{a}$ $2 \mu \mathrm{m}$. As partículas menores que $0,5 \mu \mathrm{m}$, como as partículas virais, são levadas por difusão e localizadas nas superfícies alveolares.

Se o material for depositado no epitélio brônquico, poderá ser removido pelos macrófagos alveolares ou permeabilizados na corrente sangüínea ou linfática. Essa depuração demora de dias a meses.

As fibras, partículas com um comprimento três vezes maior que sua largura, se depositam por mecanismos similares aos das partículas. Fibras como as de asbesto, geralmente lineares, se depositam em sentido longitudinal no brônquio. No entanto, fibras de crisólitos, de forma serpenteada, depositam-se nas bifurcações. Em relação a enfermidades pulmonares e asbesto, associa-se ao mesotelioma com fibras de $5 \mu \mathrm{m}$ de comprimento por $0,1 \mu \mathrm{m}$ de diâmetro. $\mathrm{O}$ câncer pulmonar é mais freqüente com fibras maiores que $10 \mu \mathrm{m}$ e com diâmetros maiores que $0,15 \mu \mathrm{m}^{(21)}$.

\section{c) A poluição e o sistema mucociliar}

O sistema respiratório está recoberto por um engenhoso meio de defesa, o sistema mucociliar, que transporta o muco e as partículas retidas, desde as porções distais até a faringe, onde são deglutidas. 
Assim, as características do muco são importantes. Se muito líquido, os cílios não vão conseguir mobilizálo, como se estivessem batendo na água. Se muito espesso, igualmente não será transportado, pois os cílios não terão força para isso.

A viscoelasticidade do muco pode ser influenciada pelo meio ambiente. Em dias de muita poluição (concentrações de material particulado, $\mathrm{SO}_{2}$, hidrocarbonetos de diversos tipos, metais pesados e uma infinidade de outras substâncias), a elasticidade do muco diminui. Gera-se, então, a tosse, com a intenção de provocar uma corrente de ar para forçar o deslocamento e desobstruir os brônquios, já que os cílios não conseguem cumprir seu papel. É, por exemplo, o caso do fumante crônico, que tem seu muco alterado.

\section{RELAÇÃO ENTRE A POLUIÇÃO AMBIENTAL E ENFERMIDADES DAS VIAS AÉREAS}

Nos últimos cinqüenta anos, vários estudos mostram que a asma e outras enfermidades alérgicas têm aumentado:

1. Burr et al. ${ }^{(1,22)}$, realizaram um estudo, comparando populações escolares do mesmo grupo etário (idade de doze anos), no sul de Gales, em um intervalo de quinze anos. Encontraram que a asma aumentou de 6 para $12 \%$ e a dermatite atópica de 5 para $12 \%$.

2. Em Aberdeen (Inglaterra), Russel et al. demonstraram $^{(2,22)}$, em um período de trinta anos (1964-94), que o diagnóstico da asma tem aumentado, de 4,1\%, em 1964, a 10,2\%, em 1989, e 19,5\% em 1994 e a dermatite atópica de 5,3\%, em 1964, a 12\%, em 1989, e 17,7\% em 1994.

3. Haahtela et al. ${ }^{(23)}$, ao analisarem os registros dos recrutas militares na Finlândia, de 1926 até 1961 e de 1961 até 1989, encontraram um aumento, no primeiro intervalo, de $0,02 \%$ a $0,08 \%$, e, no segundo intervalo, de $0,08 \%$ a $1,79 \%$ (incremento de vinte e duas vezes).

Ainda que não possa precisar quais os fatores que têm contribuído com o aumento das enfermidades das vias aéreas nas últimas três a quatro décadas, existem dados que sugerem que, em grande parte, ele se deva às mudanças nas condições de vida, em associação com a poluição ambiental. O uso de derivados de petróleo para o transporte e na indústria aumentou as concentrações atmosféricas de hidrocarbonetos, óxidos de nitrogênio, $\mathrm{O}_{3}$ e $\mathrm{PM}_{10}$.

Um estudo, no Japão ${ }^{(4)}$, demonstrou uma alta incidência de rinoconjuntivite nos indivíduos que vi- vem próximos a estradas com um intenso tráfego as vinte e quatro horas do dia, em comparação com os que vivem na proximidade de estradas com pouco trânsito, com concentrações similares de pólens. O trabalho sugere que, provavelmente, o fator principal desta disparidade seja a poluição emanada a partir da combustão de automotores.

A reunificação da Alemanha também proporcionou uma excelente oportunidade para estudar populações geneticamente similares que vivem em meios ambientes diferentes. Von Mutius e colegas ${ }^{(5)}$ demonstraram que as enfermidades alérgicas das vias respiratórias são mais comuns na Alemanha Ocidental que na Oriental, enquanto que, nesta última, é mais freqüente a bronquite crônica. Os autores sugerem que isso seja conseqüência dos diferentes tipos de poluentes que predominam nas cidades: $\mathrm{NO}_{2}$ e poluentes derivados de petróleo na Alemanha Ocidental e $\mathrm{SO}_{2}$ e fuligem de carvão na Alemanha Oriental. Esses mesmos autores ${ }^{(24)}$, ao compararem os métodos de calefação e de cozinha e as enfermidades alérgicas em ambos os segmentos da Alemanha, encontraram que a prevalência de atopia é muito maior nas crianças alemãs ocidentais, que vivem em residências com cozinhas a gás ou a querosene e calefação central, em comparação às crianças que vivem em lares onde as cozinhas são a lenha ou a carvão, mostrando os possíveis efeitos deletérios dos poluentes derivados do petróleo.

\subsection{A poluição induzindo a asma}

Vários estudos epidemiológicos recentes têm confirmado a suspeita geral de que a poluição influi na asma:

1. Em Barcelona (1983), Usetti et al. ${ }^{(25)}$ encontraram uma clara correlação entre as concentrações de óxidos de nitrogênio e as internações por asma.

2. Weeks et al. ${ }^{(26)}$ investigaram os efeitos do $\mathrm{NO}_{2}$, em sessenta e duas crianças asmáticas com idades entre sete a onze anos por duas semanas. Asmáti$\cos$, que viviam em ambientes com maiores concentrações desse poluente, apresentavam crises mais freqüentes de broncoespasmo e índices obstrutivos mais acentuados. As casas que apresentavam maiores níveis de $\mathrm{NO}_{2}$ eram aquelas onde havia fumantes, localizadas em ruas ou avenidas de muito trânsito e que usavam cozinhas à base de derivados de petróleo.

3. Em relação às partículas respiráveis $\left(\mathrm{PM}_{10}\right)$ Schwartz et al. ${ }^{(8)}$, ao correlacionarem as consultas 
por crises de asma nos asmáticos menores que sessenta e cinco anos, nas emergências, encontraram uma clara correlação entre o número de consultas e a exposição a $\mathrm{PM}_{10}$. O melhor dados preditivo foi a média de exposição dos quatro dias prévios à consulta. O interessante foi que as médias nunca excederam a $70 \%$ da concentração mínima recomendada por organismos norte-americanos. Devido a isso, os autores sugeriram uma revisão dos níveis mínimos.

4. Davies et al. ${ }^{(26)}$ assinalam que a inalação de ozônio aumenta a hiperreatividade brônquica e induz o broncoespasmo. Isso não ocorreu somente em asmáticos, mas, também, em indivíduos normais.

5. A inalação de $\mathrm{SO}_{2}$ induz broncoconstrição, tanto em asmáticos como em indivíduos normais. A inalação profunda e o exercício potencializam esses efeitos. Balmes et al. ${ }^{(27)}$ demostraram que, respirando $500 \mathrm{ppb}$ de $\mathrm{SO}_{2}$ por três minutos, desencadeia-se broncobstrução, sibilância, dor torácica e dispnéia em asmáticos leves e moderados.

\subsection{Efeito dos poluentes na hiperreatividade brônquica}

Vários estudos, em laboratório, têm demonstrado que os poluentes aumentam a hiperreatividade brônquica dos asmáticos aos alérgenos inalados:

1. Molfino et al. ${ }^{(28)}$ demonstraram que a exposição, por uma hora a 120 ppb de ozônio, aumenta a resposta brônquica a alérgenos de ambrósia, em asmáticos sensíveis a este pólen. Os autores encontraram que a dose de alérgeno, requerida para diminuir o VEF, em 15\%, diminuía praticamente à metade, depois da exposição ao $\mathrm{O}_{3}$.

2. A pré-exposição de uma combinação de 400 ppb de $\mathrm{NO}_{2}$ e 200 ppb de $\mathrm{SO}_{2}$ também reduz significativamente a dose de alérgeno capaz de provocar broncoespasmo ${ }^{(29)}$. Esse aumento de sensibilidade persiste por até quarenta e oito horas, sendo máxima às vinte e quatro horas depois da exposição ${ }^{(30)}$.

\subsection{Mecanismos pelos quais a poluição aumen- ta a sensibilização aos alérgenos}

Ainda que os mecanismos, pelos quais a poluição do meio ambiente aumenta a sensibilização a diversos antígenos, não estejam em definidos, os dados atuais sugerem que os poluentes possam aumentar a antigenicidade de partículas ou, por outro lado, possam tornar o organismo mais suscetível de ser sensibilizado. Um estudo, levado a cabo por Behrendt et al. ${ }^{(31)}$, demonstrou que os pólens, obtidos nas proximidades de estradas de alto trânsito de veículos, encontravam-se cobertos por numerosas partículas (de $5 \mu \mathrm{m}$ de diâmetro em média). Esses pólens foram incubados em soluções por duas a cinco horas e, posteriormente, observadas alterações morfológicas nos mesmos. Ao dosar as frações alergênicas, extraídas em meio aquoso, observou-se um aumento nas concentrações de alérgenos.

Estudos, em animais e em humanos, sugerem que a sensibilização induzida pela poluição poderia ser uma conseqüência de um aumento da IgE. Em um estudo realizado por Berciano et al. ${ }^{(32)} \mathrm{com}$ trezentas e sessenta e três crianças não-atópicas, menores de doze anos, demonstrou-se que o grau de poluição, nas áreas onde viviam, correlacionava-se significativamente com o aumento de IgE sérica.

Outro estudo, realizado na Alemanha Oriental ${ }^{(33)}$, com crianças entre os seis e os doze anos, demonstrou que os níveis séricos de $\operatorname{IgE}$ de crianças que viviam com fumantes eram mais elevados que aqueles dos que conviviam sem fumantes. Diaz-Sanchez et al. ${ }^{(34)}$, estudando o efeito direto das partículas liberadas por motores diesel (PLMD) na mucosa nasal de indivíduos normais, observaram que as PLMD aumentavam significativa e exclusivamente a IgE, sem efeito sobre os outros isótopos de imunoglobulina. $\mathrm{O}$ cultivo de plasmócitos com PLMD demonstrou que aumentava o número de plasmócitos produtores de IgE e o mRNA para a cadeia e.

\subsection{A poluição e o epitélio respiratório na in- dução de enfermidades das vias aéreas}

As modificações ou alterações do epitélio respiratório têm repercussões diretas sobre o mecanismo funcional respiratório. Numerosos estudos têm demonstrado que a poluição induz um dano epitelial e alterações no mecanismo ciliar, permitindo uma maior penetração e acesso de partículas e alérgenos às células do sistema imune.

\subsubsection{Estudos in vivo}

1. A inalação de ozônio produz dano epitelial e um aumento da resposta inflamatória das vias aéreas, como indicam estudos da composição do lavado nasal e broncoalveolar (LBA). Observa-se um incremento da concentração de desidrogenase láctica, albumina, proteína total, número aumentado de neutrófilos, eosinófilos, células mononucleares, fibronectina, $\alpha-1$ antitripsina, IL-6, IL-8, GM-CSF e prostaglandina E2, depois da inalação de ozônio ${ }^{(35)}$; 
2. Peden et al. ${ }^{(36)}$ demonstraram que a inalação prévia de 400 ppb de $\mathrm{O}_{3}$ estimula a liberação de proteína cariônica eosinofílica (PCE) induzida por alérgenos, sem afetar o número de eosinófilos, o que sugere que $\mathrm{o}_{3}$ aumentaria a capacidade de resposta do eosinófilo;

3. estudos similares, com inalação de $\mathrm{NO}_{2}$ em indivíduos normais, demonstraram que o número de linfócitos, macrófagos alveolares, lisossomas positivos e mastócitos aumentam no LBA ${ }^{(37)}$.

4. a exposição de portadores de rinite alérgica por seis horas a 400 ppb de $\mathrm{NO}^{2}$ não mostrou modificações na resistência da via aérea nasal (RVAN), nem tampouco modificações nas concentrações de PCE, triptase ou mieloperoxidase no lavado nasal (LN). Quando esses mesmos pacientes eram submetidos a provocação eram submetidos a provocação com alérgenos específicos (prévia inalação de $\mathrm{NO}_{2}$ ), aumentava-se significativamente a PCE, mas não a triptase, nem a mieloperoxidase. Tal observação sugere que o $\mathrm{NO}_{2}$ também aumentaria o nível de resposta dos eosinófilos ${ }^{(26)}$.

\subsubsection{Estudos in vitro}

As células epiteliais sintetizam uma variedade de citocinas proinflamatórias que, além de modular a síntese de IgE, podem influenciar o crescimento, diferenciação, proliferação e ativação de eosinófilos, mastócitos, macrofágos e linfócitos ${ }^{(38)}$. Em relação à poluição, alguns estudos têm mostrado que:

1. a exposição de células epiteliais bronquiais a concentrações de 400 até 800 ppb de $\mathrm{NO}_{2}$ aumenta a permeabilidade epitelial, diminui a atividade ciliar e libera mediadores proinflamatórios (LTC4, GM-CSF, TNF- $\alpha$ e IL-8) ${ }^{(39)}$;

2. similarmente, em outro trabalho ${ }^{(40)}$, observou-se que essas células, ao serem expostas a concentrações ambientais de $\mathrm{O}_{3}$ (10-50 ppb) liberavam IL-8, GM-CSF, TNF- $\alpha$ e ICAM-1 sóluvel;

3. ao submeter as células do epitélio brônquico às PLMD, observou-se que esses poluentes diminuíam a freqüência dos batimentos ciliares e aumentavam a secreção de IL- $8{ }^{(41)}$;

4. algumas evidências assinalam diferenças entre o epitélio brônquico de um indivíduo normal e de um atópico. Calderón et al. ${ }^{(42)}$, cultivando células epiteliais a partir de biópsias nasais de indivíduos não atópicos e não-riníticos, de pacientes atópicos nãoriníticos (dermatite atópica) e de pacientes com rinite alérgica, demonstraram que as células do grupo de riníticos sintetizavam quantidades significativamente maiores de GM-CSF, IL- 8 e TNF- $\alpha$ que as células dos pacientes com eczema atópico, que, por sua vez, liberavam quantidades maiores dessas citocinas que as células de indivíduos normais;

5. ao se investigarem os efeitos dos meios de cultura de células de epitélio brônquico, previamente expostas a concentrações de $50 \mathrm{ppb}$ de $\mathrm{O}_{3}$ por seis horas, observou-se que esses meios produziam um aumento da adesão e da quimiotaxia de eosinófilos, quando comparados com meios celulares não expostos ao ozônio ${ }^{(26)}$.

Os mecanismos pelos quais os poluentes exercem seus efeitos na árvore respiratória são resumidos na Tabela III.

\section{Tabela III - Efeitos patogênicos dos poluentes na} função respiratória

A. Indiretos

- modulação da alergenicidade dos aeroalérgenos

\section{B. Diretos}

- diminuição da atividade ciliar;

- produção de dano epitelial e aumento da permeabilidade da mucosa brônquica;

- diminuição da produção dos antioxidantes gerados naturalmente;

- indução da secreção de citocinas proinflamatórias e a expressão de moléculas de adesão, que orquestram, por sua vez, as funções de células inflamatórias.

A extensa literatura provê claras evidências de que a poluição interfere de maneira complexa com os alérgenos e, também, com os mecanismos de defesa do trato respiratório, de modo que todos os esforços devem ser envidados, no sentido de diminuir a exposição tanto aos alérgenos quanto aos poluentes do ar.

\section{MEDIDAS PREVENTIVAS}

A simples ventilação natural é uma boa medida em qualquer domicílio. Falar, em nosso meio, de filtros de ar de alta eficiência, (portáteis ou fixos), precipitadores eletrostáticos ou geradores de íons negativos e aparelhos com absorventes (carvão ativado) é, no momento, uma utopia.

Os estudos de análises de contaminantes em móveis do domicílio têm demonstrado que enormes 
quantidades de comida, poeira doméstica, epitélios de animais, resíduos de artrópodes, esporos de fungos, algas, restos de alimentos, de vegetais e bactérias, são encontradas nos colchões, sofás, almofadas, tapetes, cadeiras e assentos acolchoados. $\mathrm{O}$ envelhecimento dos materiais com que são feitos esses artefatos leva a um fracionamento das fibras sintéticas, contribuindo para aumentar ainda mais os poluentes domiciliares ${ }^{(43)}$. Um trabalho interessante, realizado por Strachan ${ }^{(44)}$, sobre os efeitos do meio-ambiente domiciliar no curso da asma em adolescentes, mostrou que há associação entre o agravamento da asma e a antigüidade dos móveis, incluídos colchões e almofadas feitas de plumas.

\section{UMA EXPERIÊNCIA LATINOAMERICANA}

No Brasil, durante o mandato presidencial de Juscelino Kubitschek (na década de 50) foram criados vários "pólos petroquímicos", com a intenção de concentrar indústrias afins em áreas consideradas, naquela época, como "estratégicas". Um desses pólos petroquímicos constitui a cidade de Cubatão, localizada a $12 \mathrm{Km}$ do porto de Santos e a 64 Km da cidade de São Paulo. A cidade de Cubatão, com uma população estimada de noventa mil habitantes, está localizada ao pé de uma ao pé de uma cadeia montanhosa, chamada "Serra do Mar", a qual corre paralela à costa marítima.

Seu clima é nitidamente tropical úmido, com um dos maiores índices pluviométricos do Brasil e uma umidade relativa contínua, acima de $70 \%$.

A cidade de Cubatão experimentou um rápido desenvolvimento e não tardaram a aparecer conseqüências da industrialização, como a eliminação sustentada da vegetação circundante, a contaminação, por produtos químicos, de rios e manguesais (com o desaparecimento de peixes). A atmosfera tornou-se poluída, condição favorecida pelos escassos ventos.

Ao final dos anos 80, devido a uma maior conscientização dos problemas relativos à poluição ambiental, levaram o governo brasileiro e, em especial, os empresários, a tomar medidas severas com o objetivo de controlar a emissão de poluentes e preservar o meio-ambiente.
O Prof. Júlio Croce et al. ${ }^{(45)}$ realizaram um estudo das enfermidades respiratórias (asma, rinite e bronquite crônica) em dois períodos:

a) em 1982: antes das medidas de controle ambiental e,

b) em 1988: depois da aplicação de medidas de saneamento.

Os poluentes detectados em ambas as oportunidades na cidade de Cubatão foram: (Tabela IV).
Tabela IV - Poluentes ambientais detectados em Cubatão(SP) antes (1982) e depois (1988) da implantação de medidas de controle ambiental

\begin{tabular}{ccc}
$\begin{array}{c}\text { Emissão } \\
\text { (Julho/1982) } \\
\text { Kg/dia }\end{array}$ & $\begin{array}{c}\text { Emissão } \\
\text { (Dezembro/1988) } \\
\text { Kg/dia }\end{array}$ & $\begin{array}{c}\text { Nível de Controle } \\
\%\end{array}$ \\
\hline 236.600 & 70.782 & 70 \\
2.620 & 200 & 92 \\
8.736 & 433 & 95 \\
61.085 & 52.249 & 14 \\
90.000 & 19.950 & 78 \\
78.353 & 49.527 & 37 \\
$149 \mu \mathrm{g} / \mathrm{m} 3$ & $97 \mu \mathrm{g} / \mathrm{m} 3$ & 35 \\
\hline
\end{tabular}

Foram entrevistadas setecentas e cinquenta pessoas em 1982 e um mil e sessenta e cinco indivíduos, em 1988. Foram apontados os sintomas das vias respiratórias relatados pelos entrevistados. Os resultados estão mostrados na Tabela V.

\begin{tabular}{|c|c|c|}
\hline Enfermidade & 1982 & 1988 \\
\hline Asma & $14,1 \%$ & $7,23 \%$ \\
\hline Rinite & 8,5 & $5,07 \%$ \\
\hline Bronquite crônica & $3,25 \%$ & $1,52 \%$ \\
\hline Total & $25,85 \%$ & $13,82 \%$ \\
\hline
\end{tabular}

As medidas de controle ambiental tomadas foram:

1. Concordância e compromisso por parte das indústrias e comunidades em cumprir as medidas de controle ambiental;

2. Mudança da população que vivia ao redor das indústrias para uma area distante $5 \mathrm{~km}$, com canalização da água e esgoto; 
3. Colocação de filtros de líquidos nos esgotos industriais, além de filtros de ar nos dutos emissores de gases, fumaça ou combustão;

4. Armazenagem controlada de produtos tóxicos;

5. Noções de higiene pessoal e comunitária intensiva, na população;

6. Controles periódicos, por parte das autoridades, das emissões de cada indústria, com penalizações nos casos de negligência.

\section{CONCLUSÕES}

A asma é uma enfermidade que vem aumentando tanto em países desenvolvidos quanto naqueles em vias de desenvolvimento. Uma grande variedade de poluentes, orgânicos e não-orgânicos, estão associados direta e indiretamente a esse aumento. $\mathrm{Na}$ América Latina, onde as noções sobre o meio-ambiente e sobre as fontes poluidoras são escassas, não há estudos sobre a poluição ambiental e o aumento da asma, com a exceção de São Paulo.

Esta breve revisão tem a intenção de fornecer subsídios para um melhor entendimento da contaminação do meio-ambiente e das enfermidades respiratórias, assim como também ser um incentivo à tomada de consciência, para buscar soluções próprias para cada região. A conscientização, tanto a nível médico como a público, levará à consecução de soluções viáveis e práticas.

CROCE M et al. Environmental pollution and respiratory allergy. Medicina, Ribeirão Preto, 30: 144-153, jan./march 1998.

ABSTRACT: In the first part of this review, we present the most proeminent biolofical or nonbiological atmospheric pollution agents of home enviroment. Then, we discuss pathogenic mechanisms of respiratory diseases triggered by there agents. Finally, we show the effect of environmental intervention in the reduction of hoth polluent emission and prevalence of respiratory disease in a highly polluted industrial area close to São Paulo city.

UNITERMS: Environmental Pollution. Respiratory Hypersensitivity. Allergy and Immunology.

\section{REFERÊNCIAS BIBLIOGRÁFICAS}

1 - BURR ML et al. Changes in asthma prevalence: two surveys 15 years apart. Arch Dis Child 64: 1452-1456, 1989.

2 - BURNEE PGJ; CHINM S \& RONA RJ Has the Prevalence of asthma increased in children? Evidence from the national study of health and growth 1973-86. BMJ 300: 1306-1310, 1990.

3 - NINAN TK; RUSSEL G. Respiratory symptoms and atopy in Aberdeen schoolchildren: Evidence from surveys 25 years apart. BMJ 304: 873-875, 1992.

4 - ISHIZAKI T et al. Studies of prevalence of Japanese cedar pollinosis among residents in a densely cultivated area. Ann Allergy 58: 265-270, 1987.

5 - von MUTIUS E et al. Prevalence of asthma and allergic disorders among children in united Germany. BMJ 305: 1395-1399, 1992.

6 - SALDIVA PHN et al. Association between air pollution and mortality due to respiratory diseases in children in São Paulo, Brazil: A preliminary report. Environ Res 65: 218-225, 1994.

7 - SOYSETH V; KONGERUD J \& BOE J. Postnatal maternal smoking increases the prevalence of asthma but not of hondrial hyperresponsiviness or atopy in their children. CHEST 107: 389-394, 1995.
8 - SCHWARTZ $\mathrm{J}$ et al. Particulate air pollution and hospital emergence room visits for asthma in Seattle. Am Rev Respir Dis 147: 826-831, 1993.

9 - UTELL MJ \& SAMET JM. Environmentally mediated disorders of the respiratory tract. Med Clin North Am 74: 291-306, 1990.

10 - PLATTS-MILLS TAE \& DE WEECK AL. Dust mites allergens and asthma - a worldwide problem. J Allergy Clin Immunol 83: 416-417, 1989.

11 - Di NICOLO R; NELSON RP \& FERNÁNDEZ-CALDAS E. Allergen-specific IgE levels in children presenting to the emergency room with acute asthma. J Allergy Clin Immunol 87: 234-238, 1992.

12 - GELBER L; POLLART S \& CHAPMAN MD. Serum IgE antibodies and allergen exposure as risk factors for acute asthma. J Allergy Clin Immunol 85: 193-199, 1990.

13 - MICHEL O; GINANNI R \& DUCHATEAU J. Domestic endotoxin exposure and clinical severity of asthma. Clin Exp Allergy 66: 1059-1064, 1991.

14 - SPIEKSMA FThM \& SPIEKSMA-BOEZEMAN MIA. High altitude and house dust mites. BMJ 1: 82-84, 1971.

15 - VERVLOET D; PENAUD A \& RAZZOUK H. Altitude and house dust mites. J Allergy Clin Immunol 69: 290-296, 1982. 
16 - SÁNCHEZ MEDINA M; FERNÁNDEZ-CALDAS E \& TRUDEAU WL. Prevalence of specific $\lg E$ to 5 diferent mites species in Bogotá, Colombia. J Allergy Clin Immunol 85: 185-199, 1990.

17 - ANDRADE D; CHARPIN D \& BIRNBAUM J. Indoor allergen levels in day nurseries. J Allergy Clin Immunol 95: 11581163, 1995.

18 - ANDERSON MC; BAER H \& OHMAN JL Jr. A comparative study of the allergens of cat urine, serum, saliva and pelt. $\mathbf{J}$ Allergy Clin Immunol 76: 563-569, 1985.

19 - SCHOU C \& LOWENSTEIN H. Purification and characterization of the important dog allergen Can d I (Ag 13). J Allergy Clin Immunol 85: 170-177,1990.

20 - HALPERN WE; GOODMAN M \& STAYNER L. Nasal cancer in a worker exposed to formaldehyde. JAMA 249: 510-514, 1983.

21 - LIPPMANN M. Asbestos exposure indices. Environ Res 46: 86-94, 1988.

22 - OMRAN M \& RUSSEL G. Continuing rise in the prevalence of asthma-like symptoms and diagnosed atopic disease in Aberdeen school children. Eur Respir J 8: 495, 1995. (.Supplement 19).

23 - HAAHTELA T et al. Prevalence of asthma in Finnish young men. BMJ 301: 266-268, 1990.

24 - von MUTIUS E; MARTINEZ FD \& NICOLAI T. Skin test reactivity and coal burning. J Allergy Clin Immunol 95: 211, 1995 (Abstract).

25 - USETTI P et al. Another asthma outbreak in Barcelona: Role of oxides of nitrogen. Lancet 1: 156, 1984.

26 - DAVIES RJ et al. Air pollution and asthma: The role of epithelial cells. In: CHANEZ P ed. et al. From Genetics to Quality of Life. The Optimal Treatment and Management of Asthma. Proceedings XVth World Congress of Asthmology. Montpellier, April 24-27, 1996. Hogrefe and Huber Publishers, Seattle. p. 90-97, 1996.

27 - BALMES JR; FINE JM \& SHEPPARD D. Symptomatic broncho-constriction after short-term inhalation of sulfur dioxide. Am Rev Respir Dis 136: 1117-121, 1987.

28 - MOLFINO MA et al. Effect of low concentrations of ozone on inhaled allergen responses in asthmatic subjects. Lancet 338: 199-203, 1991.

29 - DEVALIA JL et al. Effect of nitrogen dioxide and sulpjhur dioxide on airways response of milf asthmatic patients to allergen inhalation. Lancet 344: 1668-1671, 1994.

30 - RUSKNAK C; DEVALIA JL \& DAVIES RJ. Exposure to the combination of $200 \mathrm{ppb}$ sulphur dioxide and $400 \mathrm{ppb}$ nitrogen dioxide increases the airway response of mild asthmatics to allergen inhalation in a time-lagged manner. Eur Respir J 8: 572s 1995, (Abstract).

31 - BEHRENDT $\mathrm{H}$ et al. Interaction between aeroallergens and airbone particulate matter. Int Arch Allergy Immunol 99: 425-428, 1992.
32 - BERCIANO FA et al. Serum levels of total lgE in non-allergic children: Influence of genetic and environmental factors. Allergy 42: 276-283, 1987.

33 - WJS T et al. Indoor factors and IgE levels in children. Allergy 49: 766-771, 1994.

34 - DIAZ-SANCHES D et al. Diesel exhaust particles induce local IgE production in vivo and alter the pattern of IgE messenger RNA isoforms. J Clin Invest 94: 1417-1425, 1994.

35 - ARIS RM et al. Ozone induzd airway inflammation in human subjects as determined by airway lavage and biopsy. Am Rev Respir Dis 148: 1363-1372, 1993.

36 - PEDEN DB; SETZER Jr. RW \& DEVLIN RB. Ozone exposure has both a priming effect on allergen-induced responses and in intrinsic inflamatory action in the nasal airways of perennial allergic asthmatic. Am J Respir Crit Care Med 151: 1336-1345, 1995.

37 - SANDSTROM $\mathrm{T}$ et al. Inflammatory cell response in bronchoalveolar lavage fluid after nitrogen dioxide exposure of healthy subjects: A dose-response study. Eur Respir J 3: 332-339, 1991

38 - DEVALIA JL \& DAVIES RJ. Airway epithelial cells and mediators of inflammation. Respir Med 87: 405-408, 1993.

39 - DEVALIA JL et al. Human bronchial epithelial cell dysfunction following exposure to nitrogen dioxide, In vitro. Eur Respir J 6: 1308-1316, 1993.

40 - RUSNACK C; DEVALIA JL \& DAVIES RJ. The impact of pollution on allergic disease. Allergy 49: 21-27, 1994.

41 - BAYRAM $\mathrm{H}$ et al. Effects of diesesl exhaust particulates on the ciliary beat frequency of human bronchial epithelial cells, In vitro. Eur Respir J 8: 43s (Abstract).

42 - CALDERON MA et al. The effect of ozone (o3) on epithelial permeability and synthesis of IL-8 and GM-CSF by cultures nasal epithelial cells, from non-rhinits subjects. Clin Exp Allergy 24: 166, 1994. (Abstract).

43 - FERNANDEZ-CALDAS E \&FOX RW. Environmental control of indoor air pollution. Med Clin North Am 76: 935-952, 1992.

44 - STRACHAN DP \& CAREY IM. Home environment and severe asthma in adolescente: A population-based case control study. BMJ 311: 1053-1056, 1995.

45 - CROCE J et al. Projeto Respiração. Estudo epidemiológico da asma brônquica, rinite e bronquite crônica na cidade de Cubatão em dois períodos 1982 e 1988. Faculdade de Ciências de Santos. Disciplina de Imunologia Clínica, Santos, 1990.

Recebido para publicação em 30/01/98

Aprovado para publicação em 25/02/98 